\title{
Maltreatment in childhood substantially increases the risk of adult depression and anxiety in prospective cohort studies: systematic review, meta- analysis, and proportional attributable fractions
}

\author{
M. $\mathrm{Li}^{1}$, C. D'Arcy ${ }^{1,2}$ and X. Meng ${ }^{2,3,4 *}$ \\ ${ }^{1}$ School of Public Health, University of Saskatchewan, Saskatoon, Canada \\ ${ }^{2}$ Department of Psychiatry, University of Saskatchewan, Saskatoon, Canada \\ ${ }^{3}$ Department of Psychiatry, McGill University, Montreal, Canada \\ ${ }^{4}$ Douglas Mental Health University Institute, Montreal, Canada
}

Background. Literature supports a strong relationship between childhood maltreatment and mental illness but most studies reviewed are cross-sectional and/or use recall to assess maltreatment and are thus prone to temporality and recall bias. Research on the potential prospective impact of maltreatment reduction on the incidence of psychiatric disorders is scarce.

Method. Electronic databases and grey literature from 1990 to 2014 were searched for English-language cohort studies with criteria for depression and/or anxiety and non-recall measurement of childhood maltreatment. Systematic review with meta-analysis synthesized the results. Study quality, heterogeneity, and publication bias were examined. Initial screening of titles and abstracts resulted in 199 papers being reviewed. Eight high-quality articles met eligibility criteria. Population attributable fractions (PAFs) estimated potential preventive impact.

Results. The pooled odds ratio (OR) between any type of maltreatment and depression was 2.03 [95\% confidence interval (CI) 1.37-3.01] and 2.70 (95\% CI 2.10-3.47) for anxiety. For specific types of maltreatment and depression or anxiety disorders, the ORs were: physical abuse (OR 2.00, 95\% CI 1.25-3.19), sexual abuse (OR 2.66, 95\% CI 1.88-3.75), and neglect (OR 1.74, 95\% CI 1.35-2.23). PAFs suggest that over one-half of global depression and anxiety cases are potentially attributable to self-reported childhood maltreatment. A $10-25 \%$ reduction in maltreatment could potentially prevent 31.4-80.3 million depression and anxiety cases worldwide.

Conclusion. This review provides robust evidence of childhood maltreatment increasing the risk for depression and anxiety, and reinforces the need for effective programs and policies to reduce its occurrence.

Received 28 May 2015; Revised 17 November 2015; Accepted 18 November 2015; First published online 28 December 2015

Key words: Anxiety disorders, child abuse, childhood maltreatment, depression, population attributable fraction, projected effect.

\section{Introduction}

Childhood maltreatment is a major ethical, public health, human rights, legal and social problem (Butchart et al. 2006). It is estimated that 1 in 5 women and 1 in 13 of men worldwide have been sexually abused during childhood, while $25 \%$ of all adults report being physically abused (WHO, 2014).

Childhood maltreatment is a leading contributor to the development of depression and anxiety disorders among children and adults. It contributes to the

* Address for correspondence: X. Meng, PhD, Douglas Mental Health University Institute, McGill University, 6875 Boulevard LaSalle, Verdun H4H 1R3, Canada.

(Email: xiangfei.meng@mcgill.ca) emergence of psychopathology (McCrory et al. 2010) through many neurobiological mechanisms: (1) stress systems (Cicchetti \& Toth, 2005); (2) structural brain differences (Herringa et al. 2013), e.g. hippocampus, amygdala, corpus callosum and other white-matter tracts, and prefrontal cortex; (3) functional brain differences, e.g. hyperactivity of amygdala in response to negative facial affect; and (4) genetics and epigenetics of resilience and vulnerability. Maltreatment in childhood is also a threat to the optimal development of affective processing abilities, attachment relationships, self-system processes, peer relationships, and adaptation to school (Cicchetti \& Toth, 2005).

Depression and anxiety disorders are the major causes of psychiatric morbidity worldwide. According to the global burden of disease report 2010, depressive 
disorders contributed most to the burden of mental illness and substance use disorders (42.5\%) followed by anxiety disorders (15.3\%) (Whiteford et al. 2013). Depressive disorders also accounted for $40.5 \%$ of disability-adjusted life years caused by mental illnesses and substance use disorders, with anxiety disorders accounting for another $14.6 \%$.

Previous studies of childhood maltreatment have shown its significant impact on mental and physical health outcomes. Child abuse, including physical abuse, sexual abuse, and exposure to intimate partner violence, has been associated with psychiatric disorders, including depression, bipolar disorder, generalized anxiety disorder, alcohol and drug abuse, suicidal ideation and attempts, etc. (Afifi et al. 2014). Children from abusive families are significantly more likely to report depressive symptoms than those from non-abusive homes (Toth et al. 1992).

Reviews have also consistently shown the negative immediate and long-term psychological effects of the childhood maltreatment. Maniglio (2010, 2012) in systematic reviews of reviews found that child sexual abuse was a significant risk factor for both depression and anxiety disorders. Adults who report being abused as children exhibited more post-traumatic stress symptoms, cognitive distortion, emotional distress (including depression and anxiety disorders), eating disorders, sleep disorders, substance abuse, and avoidance (Briere \& Elliott, 1994; Chen et al. 2010; Nanni et al. 2012).

Although previous reviews have shown a significant direct relationship between childhood maltreatment and depression and anxiety, they either reviewed cross-sectional studies or studies that did not have an externally documented history of child abuse. Abuse exposure has generally been measured via recall methods which is prone to bias and false memory (Robins et al. 1985; Taylor \& Brown, 1988; Coughlin, 1990; Maughan et al. 1995; Neumann et al. 1996; Hardt \& Rutter, 2004). A substantial proportion of individuals known to have suffered abuse/maltreatment do not report such abuse when interviewed in adult life (Hardt \& Rutter, 2004). Taylor \& Brown (1988) indicated that mental health is associated with a filtering out of negative memories and/or re-representing them in nonthreatening terms. People with good functioning in adult life are apt to forget early parental negativity whereas there is a tendency for people with poor functioning to retrospectively exaggerate negativity that was not reported contemporaneously during childhood (Robins et al. 1985; Maughan et al. 1995). Similarly, Colman et al. (2015) found significant inconsistencies in the reporting of adverse childhood events between two time points 12 years apart. Concurrent mental health factors were found to influence the reporting of traumatic childhood experiences. The authors strongly suggest that studies estimating the association between adverse childhood events and mental health need to look at the consistency of the reporting such events. Further, cross-sectional studies cannot identify the temporal relationship between risk factors and outcomes. Additionally, questions have been raised concerning the use of rating scales as opposed to diagnostic instruments to measure mental illness outcomes.

Little can be found with respect to the potential impact of reducing childhood abuse in decreasing the incidence of psychiatric disorders in a population. Population attributable fractions (PAFs) are used to indicate the proportional reduction in a population of a disease (incidence or mortality) that would occur if exposure to a risk factor were reduced to an alternative ideal exposure level (Rockhill et al. 1998). PAFs have been commonly recognized as effective tools measuring the potential effects of risk factors on psychiatric disorders (Sareen et al. 2008; Bolton \& Robinson, 2010; Barnes \& Yaffe, 2011; Meng \& D'Arcy, 2013, 2014). Northridge (1995) believed that PAFs could help policy-makers in judging priorities for public health action, intervention planning and decision-making.

This study aims to: (1) systematically review the evidence for the association between childhood maltreatment and the later development of depression and anxiety using longitudinal cohort studies and studies with externally documented measures of childhood maltreatment and diagnostic measures of depression and/or anxiety; and (2) provide firm estimates of by how much the incidence of depression and anxiety in a population would be reduced if childhood maltreatment was reduced.

\section{Method}

This systematic review and meta-analysis was guided by the PRISMA guidelines, 2009 revision (Moher et al. 2009), and the Meta-analysis of Observational Studies in Epidemiology (MOOSE) recommendations (Stroup et al. 2000).

\section{Inclusion and exclusion criteria}

To be included in this review articles were evaluated for internal validity and the following inclusion and exclusion criteria: (1) be published in English within the last 25 years (1990-2014); (2) be a cohort study; (3) not using subject recall to assess childhood maltreatment; (4) give clear information on the assessment of adverse childhood experiences (e.g. types of abuse, years of age being abused, assessment and 
ascertainment tools, etc.); (5) use clear diagnosis criteria for depression or anxiety in adulthood, specifically DSM and its updates (APA, 2013), ICD-10 (WHO, 1992) or other generally accepted diagnostic criteria; (6) provide statistical indicators (e.g. relative risk) or original data to estimate the relationship between child abuse and depression/anxiety; (7) studies that measured childhood maltreatment via recall methods only or referrals without official documentary support (e.g. police records, records from social services, child protective services, and criminal court) were excluded.

\section{Search strategy}

We conducted computerized searches in the PubMed, PsycINFO, EMBASE, Medline, and Cochrane Library databases for the period from January 1990 to December 2014 for published articles. The search strategy is detailed in Supplementary Appendix 1. In addition, we manually searched other resources for other relevant studies. The reference lists of selected articles, review articles on relevant topics, and the grey literatures were also screened.

\section{Data collection and quality assessment}

The full-text article was retrieved for all studies that initially appeared to meet the inclusion criteria for further examination. Authors M.L. and X.M. independently assessed the articles for eligibility. Any disagreements among reviewers were resolved through discussion. Data on author, publication year, journal, sample size, methods, indicators, outcomes, comorbidities, adjustments, study design and results were extracted independently by the two authors. Newcastle-Ottawa Scale criteria were used to characterize study quality (Wells et al. 2012). One author of a selected article was contacted for further information. One eligible study was excluded because of duplication.

\section{Data synthesis}

The reviewed articles were grouped for five analyses: (1) any maltreatment and depression; (2) any maltreatment and anxiety; (3) physical abuse and either depression or anxiety disorders; (4) sexual abuse and either depression or anxiety disorders; and (5) neglect and either depression or anxiety disorders. We report on each analysis separately. Studies were involved in multiple separate analyses as their available data permitted.

\section{Statistical analyses}

Meta-analysis

The analyses generated pooled estimates of the effects of childhood maltreatment in general and for specific types of abuse on depression and/or anxiety. We also evaluated heterogeneity with DerSimonian and Laird $I^{2}$ statistics for each category to determine the proportion of heterogeneity that is not due to chance (Higgins et al. 2003). Funnel plots and Egger's tests were used to inspect for publication bias (Egger et al. 1997). Compared to funnel plot, Egger's test provides a more objective way to estimate the reliability of the results. If these tests show non-significant heterogeneity, we used fixed-effects model, whereas a more conservative random-effects model was used if we saw the possibility of heterogeneity. Sensitivity analysis assessed the influence of each individual study on overall estimates by recalculating odds ratios with each study being removed one at a time. The quality of each study was rated according to the NewcastleOttawa Scale, and meta-regression analyses were used to examine the impact of study quality on results. Stata v. 12, statistical software (StataCorp., USA) was used for the analyses.

\section{Calculation of projected effects (PAFs)}

PAF is the proportional reduction in average disease risk that would be achieved by elimination of an exposure of interest or its reduction to a specified level. It indicates that the proportion of people with a disease in a population that is potentially attributable to a given risk factor assuming that there is a causal relationship (Benichou, 2001). The PAF takes into account the strength of the association between the risk factor and the outcome as well as the prevalence of the risk factor. It was calculated by the following formula based on previous literature (Rockhill et al. 1998; Sareen et al. 2008; Barnes \& Yaffe, 2011):

$\mathrm{PAF}=\frac{p(\mathrm{OR}-1)}{p(\mathrm{OR}-1)+1}$,

where $p$ is the population prevalence of the exposure, and OR is the pooled odds ratio of outcomes given different categories of childhood maltreatment. In the present study, worldwide PAFs were calculated for specific types of abuse. Present worldwide prevalence estimates were obtained from the most recent review of (Stoltenborgh et al. 2015). Both self-reported and informant prevalence estimates were used to generate self-reported and informant PAFs, respectively. Informant estimates are from studies collecting data from police records, social services, child protective services, child welfare workers, or teachers.

Finally, we estimated the total number of depression and/or anxiety cases attributable to different categories of childhood maltreatment by multiplying PAF estimates and the present number of cases worldwide. We also calculated the number of cases that could 

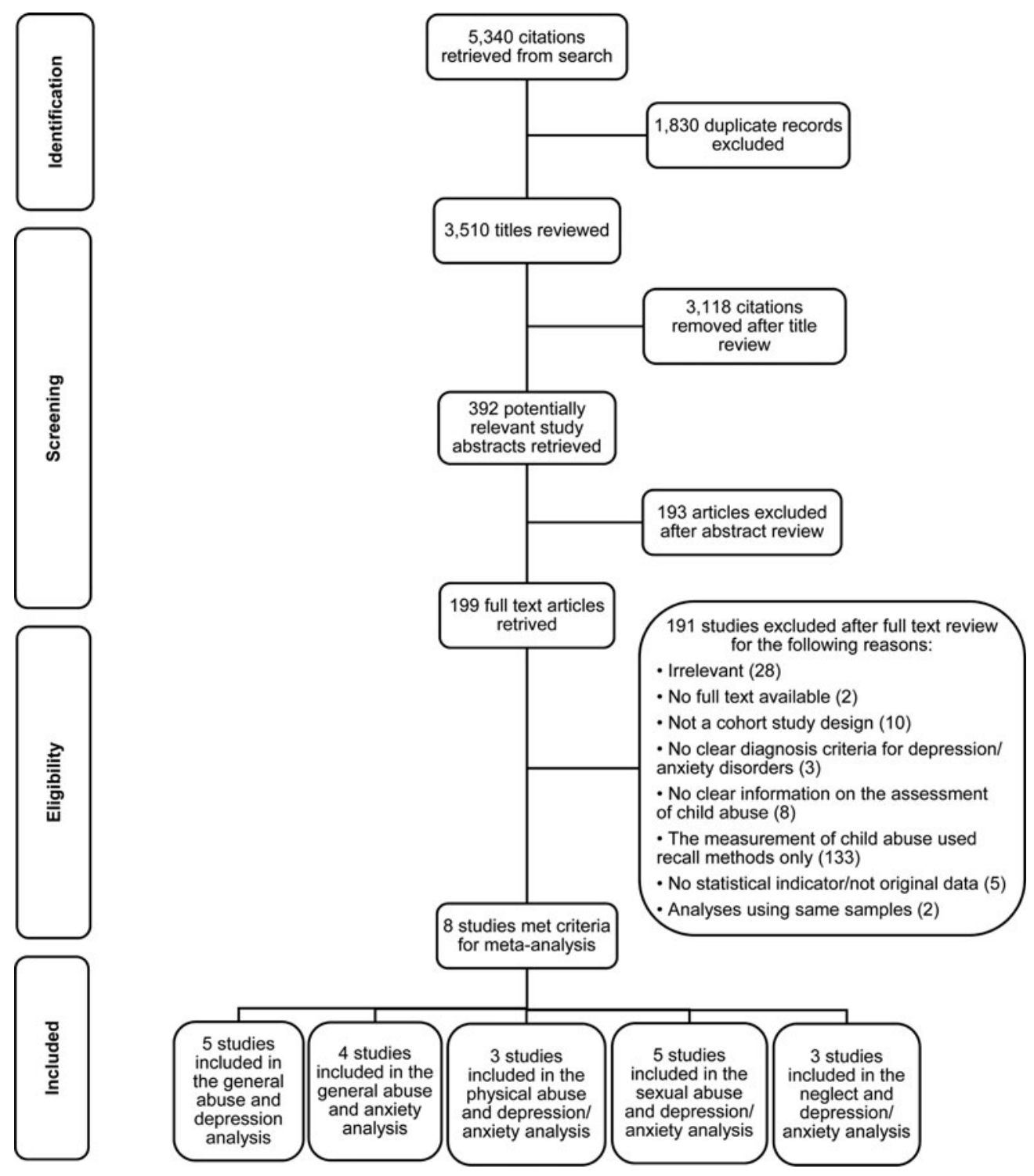

Fig. 1. PRISMA flow diagram - childhood maltreatment and later depression and/or anxiety.

potentially have been prevented if the prevalence of exposure to childhood maltreatment were $10 \%$ or $25 \%$ lower than present levels. We also calculated confidence ranges for PAF estimates, number of attributable cases, and number of cases potentially prevented by using the $95 \%$ confidence intervals (CIs) from the pooled OR estimates.

\section{Results}

\section{Meta-analysis}

Selection of articles

Fig. 1 shows the process of study selection. The initial search produced 5340 titles, from which 392 abstracts were reviewed, subsequently 199 articles were retrieved for full evaluation. Eight articles met our inclusion and exclusion criteria (see Supplementary Appendix 2).

Table 1 presents the detailed data on characteristics of the reviewed articles. The articles were assessed for quality using the Newcastle-Ottawa Quality Assessment Criteria as well as for the external ascertainment of childhood maltreatment exposure. All the included studies rated highly in terms of quality (see Supplementary Appendix 3). This quality is evident in the fact that none of the study characteristics examined had any impact on observed odds ratios in any of the analyses reported. Nor was there any publication bias observed.

\section{Relationship between any maltreatment and depression}

Five articles (Brown et al. 1999; Widom et al. 2007; Danese et al. 2009; Scott et al. 2012; Cutuli et al. 2013) 
Table 1. Summary of the studies' attributes

\begin{tabular}{|c|c|c|c|c|c|c|c|c|c|c|}
\hline $\begin{array}{l}\text { First } \\
\text { author }\end{array}$ & Year & Setting & Sample source & $\begin{array}{l}\text { Sample } \\
\text { size }\end{array}$ & Type of exposure & $\begin{array}{l}\text { Age of } \\
\text { exposure } \\
\text { (year) }\end{array}$ & $\begin{array}{l}\text { Ascertainment of } \\
\text { exposure }\end{array}$ & $\begin{array}{l}\text { Health } \\
\text { outcome }\end{array}$ & $\begin{array}{l}\text { Age of } \\
\text { outcome } \\
\text { assessed } \\
\text { (years) }\end{array}$ & $\begin{array}{l}\text { Assessment of } \\
\text { health outcome }\end{array}$ \\
\hline $\begin{array}{l}\text { Cutuli } \\
\text { et al. }\end{array}$ & 2013 & USA & $\begin{array}{l}\text { Children of primiparous } \\
\text { women }\end{array}$ & 157 & $\begin{array}{l}\text { Maltreatment in } \\
\text { general }\end{array}$ & Birth to 17.5 & $\begin{array}{l}\text { Observation, caregiver } \\
\text { interviews, reviews } \\
\text { of child protection } \\
\text { and medical records }\end{array}$ & Depression & $18-28$ & SCID \\
\hline $\begin{array}{l}\text { Cutajar } \\
\text { et al. }\end{array}$ & 2010 & Australia & Victoria residents & 5365 & Sexual abuse & Birth to 16 & $\begin{array}{l}\text { Official records from } \\
\text { VIFM }\end{array}$ & $\begin{array}{l}\text { Anxiety and } \\
\text { PTSD }\end{array}$ & $\geqslant 18$ & $\begin{array}{l}\text { Diagnosed using } \\
\text { DSM, then } \\
\text { transferred codes } \\
\text { using WHO-ICD }\end{array}$ \\
\hline Widom & 1999 & USA & General population & 1196 & $\begin{array}{l}\text { Child abuse in } \\
\text { general, physical } \\
\text { abuse, sexual } \\
\text { abuse, and neglect }\end{array}$ & Birth to 11 & $\begin{array}{l}\text { Official records from } \\
\text { the county juvenile or } \\
\text { adult criminal court }\end{array}$ & PTSD & $\geqslant 18$ & DIS \\
\hline $\begin{array}{l}\text { Scott } \\
\text { et al. }\end{array}$ & 2012 & $\begin{array}{l}\text { New } \\
\text { Zealand }\end{array}$ & National population & 1413 & $\begin{array}{l}\text { Maltreatment in } \\
\text { general }\end{array}$ & Birth to 17 & $\begin{array}{l}\text { Official records from } \\
\text { CYF }\end{array}$ & $\begin{array}{l}\text { Major } \\
\text { depressive } \\
\text { disorder and } \\
\text { anxiety }\end{array}$ & $16-27$ & CIDI \\
\hline $\begin{array}{l}\text { Widom } \\
\text { et al. }\end{array}$ & 2007 & USA & General population & 1196 & $\begin{array}{l}\text { Child abuse in } \\
\text { general, physical } \\
\text { abuse, sexual } \\
\text { abuse, neglect }\end{array}$ & Birth to 11 & $\begin{array}{l}\text { Official records from } \\
\text { the county juvenile or } \\
\text { adult criminal court }\end{array}$ & $\begin{array}{l}\text { Major } \\
\text { depressive } \\
\text { disorder }\end{array}$ & $\geqslant 18$ & DIS-III-Revised \\
\hline $\begin{array}{l}\text { Spataro } \\
\text { et al. }\end{array}$ & 2004 & Australia & Victoria residents & 3141357 & Child sexual abuse & Birth to 16 & $\begin{array}{l}\text { Official records from } \\
\text { VIFM }\end{array}$ & Anxiety & $\geqslant 18$ & $\begin{array}{l}\text { Registered cases on } \\
\text { the Victorian } \\
\text { Psychiatric Case } \\
\text { Register }\end{array}$ \\
\hline $\begin{array}{l}\text { Brown } \\
\text { et al. }\end{array}$ & 1999 & USA & General population & 776 & $\begin{array}{l}\text { Child maltreatment } \\
\text { in general, neglect, } \\
\text { physical abuse, } \\
\text { sexual abuse }\end{array}$ & $\begin{array}{l}\text { Non-specify } \\
\text { ('youth') }\end{array}$ & $\begin{array}{l}\text { Official records from } \\
\text { NYSCR and } \\
\text { retrospective } \\
\text { self-report }\end{array}$ & $\begin{array}{l}\text { Depressive } \\
\text { disorder }\end{array}$ & $\begin{array}{l}\text { Non-specify } \\
\text { ('young } \\
\text { adult') }\end{array}$ & DISC \\
\hline
\end{tabular}


were included in the analysis to examine the relationship between any childhood maltreatment and depression. Fig. $2 a$ presents the individual study, pooled estimates, and funnel plots that were used to visually assess the presence of publication bias. A random-effects model was used.

The pooled OR for depression for individuals with any type of childhood maltreatment compared to those without maltreatment history was 2.03 (95\% CI 1.373.01, $\left.\chi^{2}=10.94, I^{2}=63.4 \%, p=0.027\right)$, indicating those with a child abuse history were 2.03 times more likely to have depression than those without such history.

As shown in the funnel plot in Fig. $2 a$, all the studies were within the domain, which represents $95 \% \mathrm{CI}$ limits. No asymmetry was shown in the funnel plot. There was no evidence of publication bias (Egger's test, $p=0.46$ ).

Sensitivity analysis was used to assess the influence of each study on overall estimates by omitting one study at a time. The analysis yielded with/without childhood maltreatment ORs ranging from 1.69 (95\% CI 1.09-2.64) to 2.24 (95\% CI 1.33-3.79). The combined OR was 1.91 (95\% CI 1.27-2.85), which clearly indicates the experience of childhood maltreatment was a risk factor for depression.

\section{Relationship between any maltreatment and anxiety}

Four articles (Widom, 1999; Spataro et al. 2004; Cutajar et al. 2010; Scott et al. 2012) were used to examine the relationship between any type of childhood maltreatment and anxiety disorders. Fig. $2 b$ shows the individual study and pooled estimates, and funnel plots. A random-effects model was used.

The pooled OR for anxiety for individuals who experienced any type of childhood maltreatment compared to those who did not was 2.70 (95\% CI 2.10-3.47, $\left.\chi^{2}=6.65, I^{2}=54.9 \%, p=0.084\right)$, indicating that those who experienced child abuse were 2.70 times more likely to have anxiety disorders in adulthood than those who did not experience maltreatment.

The funnel plot in Fig. $2 b$ showed that all the studies were within the $95 \%$ CI domain. No asymmetry was found in the funnel plot. No evidence of publication bias was found (Egger's test, $p=0.26$ ).

Sensitivity analyses found that with/without childhood maltreatment ORs ranging from 2.65 (95\% CI 1.91-3.68) to 3.11 (95\% CI 2.34-4.13). The combined OR was 2.84 (95\% CI 2.19-3.68), clearly indicating that childhood maltreatment experience was a risk factor for anxiety disorders.

Relationship between physical abuse and depression or anxiety

Three articles (Brown et al. 1999; Widom, 1999; Widom et al. 2007) were used to examine the relationship 
(a) Relationship between any maltreatment and depression

Individual and combined odds ratios

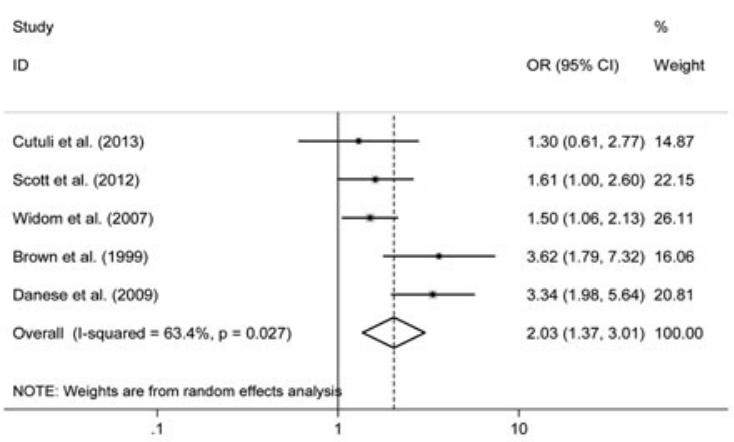

(b) Relationship between any maltreatment and anxiety Inidividual and combined odds ratios

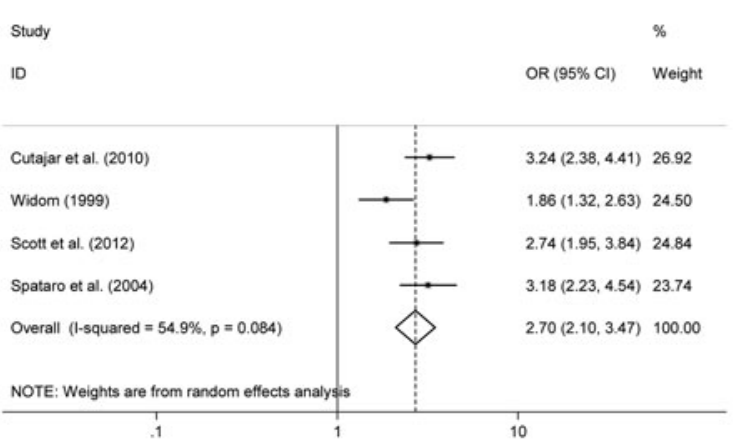

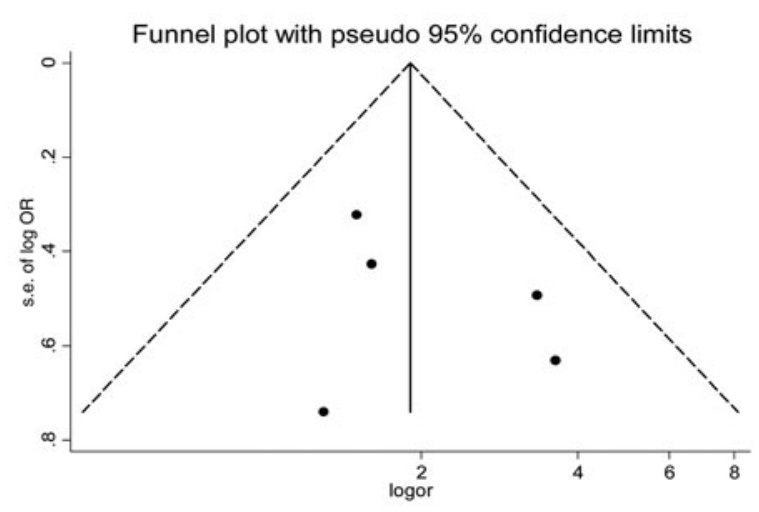

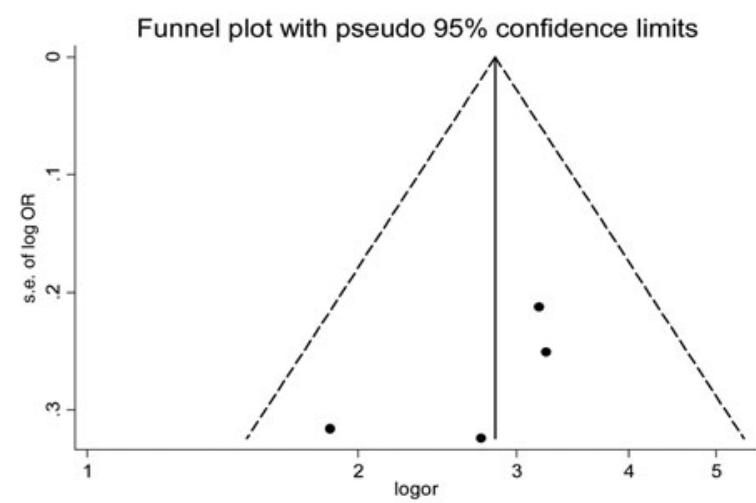

(c) Relationship between physical abuse and depression and/or anxiety

Inidividual and combined odds ratios

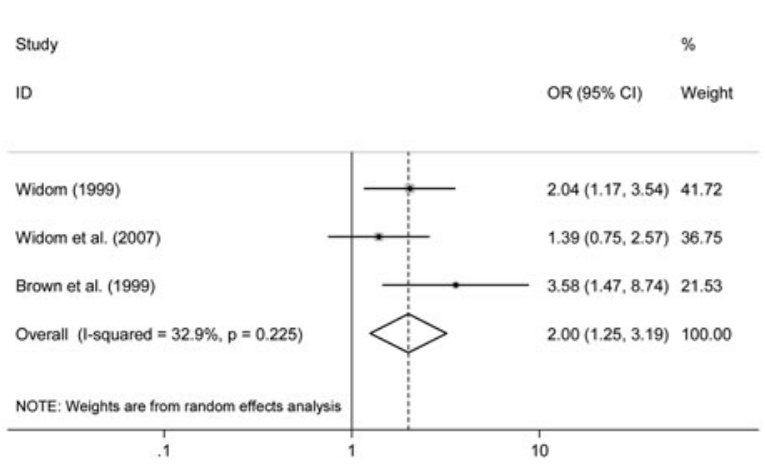

Funnel plot with pseudo $95 \%$ confidence limits

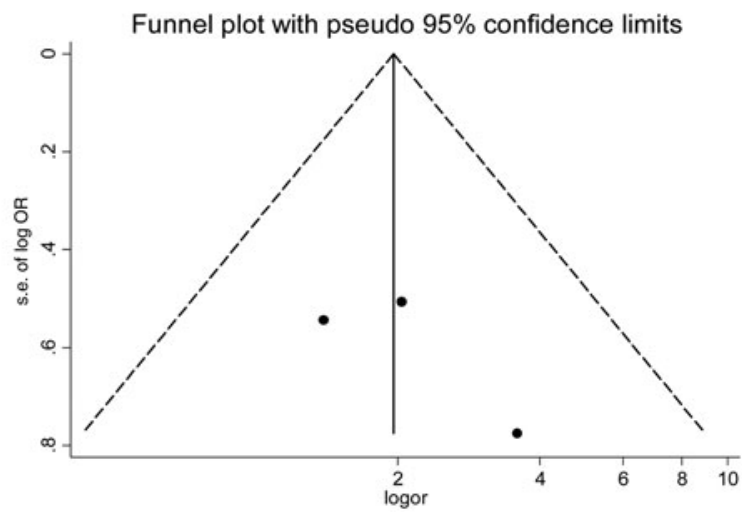

Fig. 2. Odds ratios (OR) between childhood maltreatment and depression and/or anxiety and funnel plots. In the funnel plots, the $\mathrm{x}$-axis shows the logarithmic scale of OR estimate for each study and y-axis is standard error of the logarithmic function of the OR. The dashed line represents the $95 \%$ confidence interval CI) and the point estimate of logarithmic transition of OR illustrates as the solid line. (a) Relationship between any maltreatment and depression, (b) relationship between any maltreatment and anxiety, $(c)$ relationship between physical abuse and depression and/or anxiety, (d) relationship between sexual abuse and depression and/or anxiety, (e) relationship between neglect and depression and/or anxiety.

between physical abuse and either depression or anxiety disorders. Fig. $2 c$ presents the individual study, pooled estimates, and funnel plots. A random-effects model was used. Analysis using a fixed-effects model did not affect the results.

The pooled OR for depression and/or anxiety for individuals who were physically abused in childhood compared to those who were not was $2.00(95 \% \mathrm{CI}$ $\left.1.25-3.19, \chi^{2}=2.98, I^{2}=32.9 \%, p=0.225\right)$, indicating that children who were physically abused were two times more likely to develop depression or anxiety in adulthood than those who were not.

The funnel plot in Fig. $2 c$ indicated that all the studies were within the $95 \%$ CI domain. No asymmetry 
(d) Relationship between sexual abuse and depression and/or anxiety
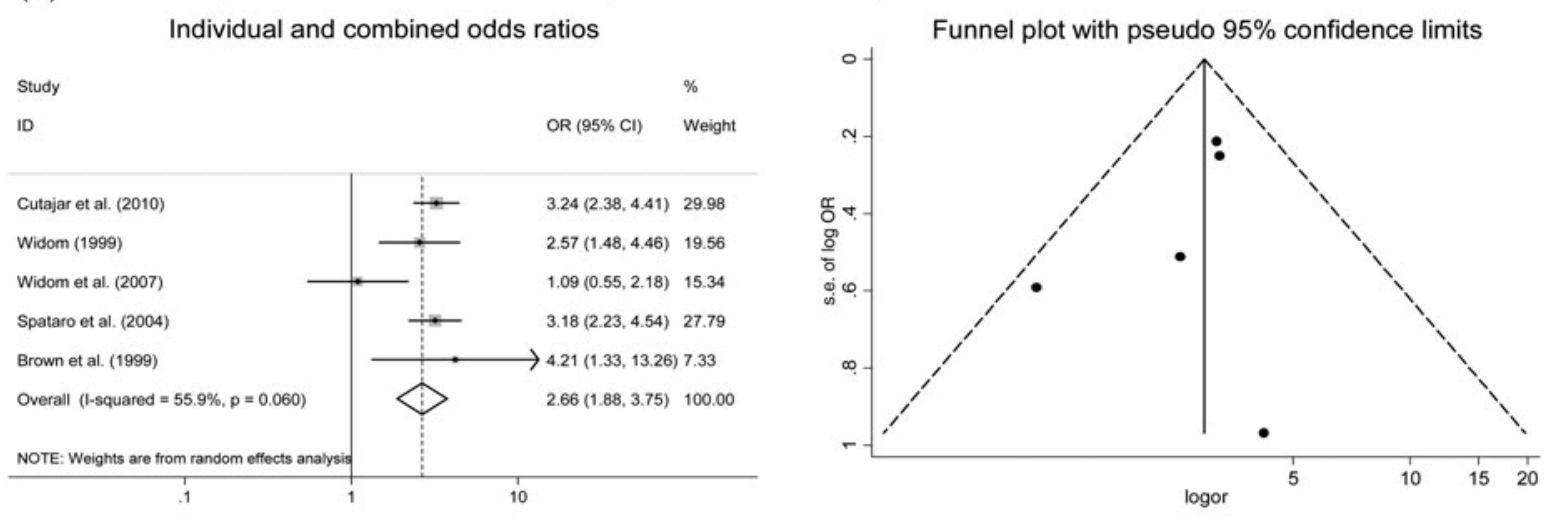

(e) Relationship between neglect and depression and/or anxiety
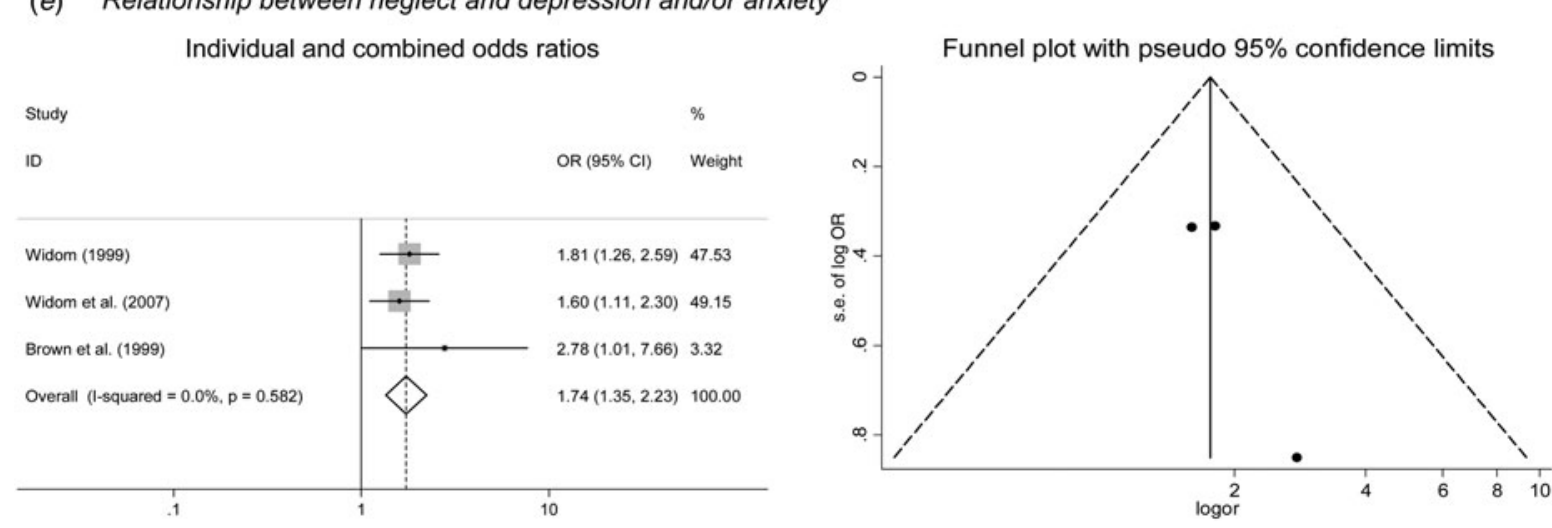

Fig. 2. (cont.)

was found in the funnel plot. No evidence of publication bias was found (Egger's test, $p=0.449$ ).

Sensitivity analysis produced with/without physical abuse ORs ranging from 1.71 (95\% CI 0.83-3.53) to 2.41 (95\% CI 1.05-5.54). The combined OR was 1.96 (95\% CI 1.02-3.78), indicating that childhood experience of physical abuse was an important risk factor for depression and anxiety disorders.

\section{Relationship between sexual abuse and depression or anxiety}

Five articles (Brown et al. 1999; Widom, 1999; Spataro et al. 2004; Widom et al. 2007; Cutajar et al. 2010) were included in the analysis of the relationship between sexual abuse and depression and anxiety disorders. Fig. $2 d$ presents the individual study and pooled estimates, and funnel plots. A random-effects model was used.

The pooled OR for depression and anxiety for individuals sexually abused in childhood compared to those who were not was 2.66 (95\% CI 1.88-3.75, $\chi^{2}=$ 9.06, $I^{2}=55.9 \%, p=0.06$ ), indicating that children who experienced sexual abuse were 2.66 times more likely to develop depression or anxiety in adulthood than those without such experience.
As shown in Fig. $2 d$, the funnel plot indicated that all the studies were within the $95 \%$ CI domain. No asymmetry was found in the funnel plot. No evidence of publication bias was found (Egger's test, $p=0.417$ ).

Sensitivity analysis yielded with/without sexual abuse ORs ranging from 2.75 (95\% CI 1.81-4.16) to 3.16 (95\% CI 2.35-4.27). The combined OR was 2.96 (95\% CI 2.22-3.95), showing that childhood experience of sexual abuse was a strong risk factor for depression and anxiety disorders.

\section{Relationship between neglect and depression or anxiety}

Three articles (Brown et al. 1999; Widom, 1999; Widom et al. 2007) contributed to the analysis of the relationship between neglect and depression and anxiety disorders. Fig. $2 e$ presents the individual study and pooled estimates, and funnel plots. A fixed-effects model was used.

The pooled OR overall for depression and anxiety for individuals experienced neglect compared to those did not experience neglect was 1.75 (95\% CI 1.37-2.24, $\left.\chi^{2}=1.08, I^{2}=0.0 \%, p=0.58\right)$, indicating that children who experienced neglect were 1.75 times 


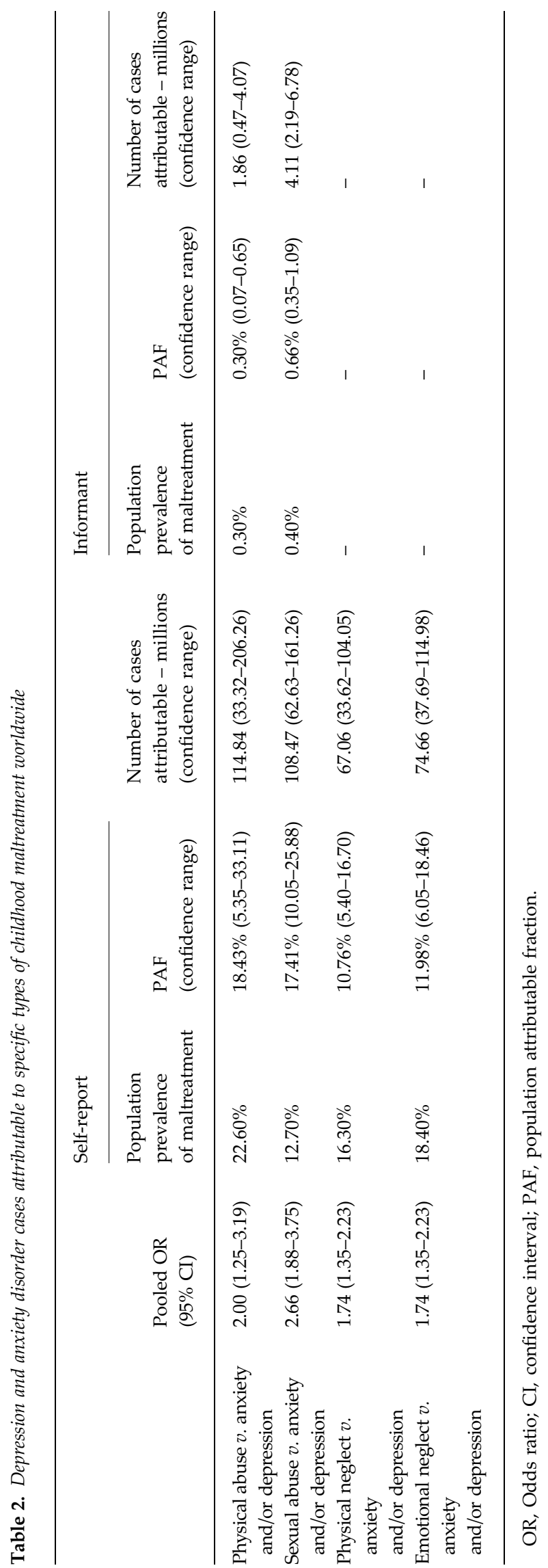

more likely to develop depression or anxiety in adulthood than those who were not neglected.

As shown in Fig. 2e, the funnel plot indicated that all the studies were within the $95 \%$ CI domain. No asymmetry was found in the funnel plot. There was no evidence of publication bias (Egger's test, $p=0.284$ ).

Sensitivity analysis for with/without neglect ORs ranged from 1.70 (95\% CI 1.07-2.70) to 1.91 (95\% CI 1.043.51). The combined OR was 1.76 (95\% CI 1.13-2.75), pointing to childhood experience of neglect as a significant risk factor for depression and anxiety disorders.

\section{Projected effects (PAFs)}

Self-reported prevalence of childhood maltreatment and $P A F s$

In 2014, the worldwide self-reported prevalence of physical abuse was $22.6 \%$ (Stoltenborgh et al. 2015). Worldwide depression and anxiety disorders are estimated to affect 350 million (WHO, 2012) and 273 million adults (Vos et al. 2012), respectively. The PAF estimate used here for the effect of physical abuse on the incidence of depression and anxiety disorders was $18.4 \%$, which indicates that nearly 115 million of depression and anxiety cases are potentially attributable to childhood physical abuse (Table 2). If the global prevalence of physical abuse was reduced by $10 \%$, we estimated that there would be 9.5 million fewer depression and anxiety cases worldwide, whereas a $25 \%$ reduction could reduce prevalence by 24.6 million cases (Fig. 3). It should be noted that the numbers of cases attributable to any specific type of abuse and any specific mental disorder maybe an overestimate due to the existence of co-morbidity among mental disorders and the potential for an individual to suffer multiple types of abuse.

The self-reported prevalence of sexual abuse is $12.7 \%$ based on the Stoltenberg et al. (2011, 2015) meta-analyses. Approximately $17.4 \%$ (over 108 million) of depression and anxiety cases in the world are potentially attributable to childhood sexual abuse. If the prevalence of sexual abuse was reduced by $10 \%$, about 9.1 million cases could potentially be prevented; a $25 \%$ reduction in sexual abuse prevalence could potentially prevent about 23.4 million cases worldwide.

It was estimated that $16.3 \%$ and $18.4 \%$ of worldwide population respectively have been exposed to physical and emotional neglect (Stoltenborgh et al. 2015). Our meta-analysis suggests about $10.8 \%$ (67 million) and $12.0 \%$ (75 million) of depression and anxiety cases respectively are potentially attributable to physical and emotional neglect. A $10 \%$ of reduction in the prevalence of physical neglect could potentially lower the number of cases of depression and anxiety by $6.1 \mathrm{mil}-$ lion globally; this number would increase to 15.4 million if the prevalence physical neglect were reduced 


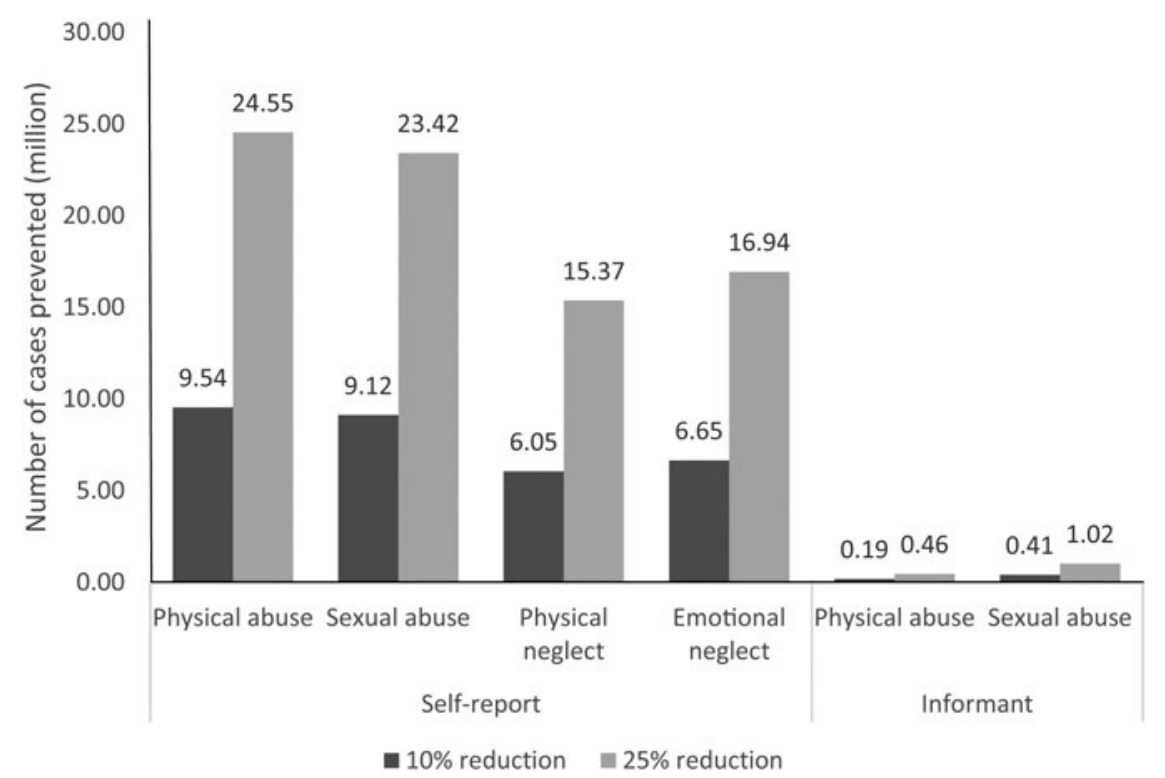

Fig. 3. Potential depression and anxiety cases that could be prevented through child maltreatment reduction worldwide.

by $25 \%$. Similarly, around 6.7 and 16.9 million of cases of depression and anxiety, respectively could be prevented by a $10 \%$ and a $25 \%$ reduction in the prevalence of emotional neglect.

Adding up specific types of maltreatment, over half (58.59\%) of depression and anxiety cases worldwide are potentially attributable to childhood maltreatment. A $10 \%$ reduction in child maltreatment could potentially prevent 31.36 million depression and anxiety cases, and a 25\% reduction could potentially prevent 80.28 million cases.

\section{Informant prevalence of childhood maltreatment and PAFs}

The informant prevalence of physical abuse was $0.3 \%$ (Stoltenborgh et al. 2015). It is estimated that $0.3 \%$ (nearly 1.9 million) of depression or anxiety cases are potentially attributable to childhood physical abuse. A 10$25 \%$ reduction of the prevalence could potentially prevent 190000 to 460000 of depression and anxiety cases.

It reported that $0.4 \%$ of the worldwide population have been exposed to sexual abuse based on informant studies (Stoltenborgh et al. 2015). The PAF estimate is $0.66 \%$, which indicates that 4.1 million of depression and anxiety cases are potentially attributable to the exposure of sexual abuse in childhood. If the prevalence of sexual abuse was reduced by $10 \%$, about 410000 cases could potentially be prevented; a $25 \%$ reduction could potentially prevent about 1020000 cases.

\section{Discussion}

This meta-analyses consistently showed significant relationships between various types of maltreatment and depression and/or anxiety outcomes. The pooled OR between any type of maltreatment and depression was 2.03 (95\% CI 1.37-3.01) and 2.70 (95\% CI 2.10 3.47) for anxiety. For specific types of maltreatment and depression or anxiety disorders, the ORs were: physical abuse (OR 2.00, 95\% CI 1.25-3.19); sexual abuse (OR 2.66, 95\% CI 1.88-3.75); and neglect (OR $1.75,95 \%$ CI 1.37-2.24).

Consistent with previous reviews, our results show childhood maltreatment is a risk factor for depression and anxiety disorders. Several meta-analyses, using less rigorous criteria for the measurement of maltreatment exposure, evaluating the short- and long-term effects of various types of childhood maltreatment on mental health support our finding that all types of child maltreatment are associated with an elevated risk of developing psychological disorders, including depression and anxiety disorders (Maniglio, 2009; Paolucci et al. 2010; Nanni et al. 2012; Norman et al. 2012).

This paper provides the first quantitative estimates on the projected reduction of mental disorders cases that could result from a reduction in child maltreatment. The PAFs estimate that over half of depression and anxiety cases worldwide are potentially attributable to childhood self-reported maltreatment. A 10$25 \%$ reduction in childhood maltreatment could potentially prevent $31.36-80.28$ million depression and anxiety cases worldwide. When using informant based reports approximately 9 million cases are attributable to childhood physical or sexual abuse. A $10-25 \%$ of reduction in the prevalence of such child abuse could potentially prevent $0.4-1$ million cases. 
Both self-reported and informant measures of maltreatment have strengths and limitations. An obvious drawback of self-reported is the reliance on retrospective memory, which is often seen as unreliable and could be biased; whereas informant reports are often reflecting the most severe cases of maltreatment. Informant measures may better assess the continuity and circumstances of maltreatment experiences, such as neglect or emotional abuse; while self-reported measures may work better for some types of maltreatment, such as sexual abuse, which may be more invisible to informants. Additionally, informant studies may substantially underestimate abuse since they are based on reports by professionals to child protective services and cover shorter periods of childhood (usually a 1-year period), compared to self-report studies. However, a conclusion as to whether self-report prevalence rates are over- or underestimates is less clear cut. Childhood maltreatment may be overestimated when chronicity is not taken into account; it could also be underestimate when abuse is measured at a single time point (Fergusson et al. 2000; Colman et al. 2015; Stoltenborgh et al. 2015).

PAF estimates provide quantitative measures of the impact that could be achieved by reducing the prevalence of childhood maltreatment on depression and anxiety. Our study strongly suggests that decreasing the amount of maltreatment in childhood should be the target for mental illness prevention and mental health promotion. This is not only because adverse experiences in childhood significantly increase the risk of adult depression and anxiety, but also because of its threats to children's development. A life-course perspective stresses the importance of early childhood experiences in setting the trajectory for future adolescent and adult risk behaviors and disease. Interventions and services for maltreatment should also promote resilience to further improve the mental health of general populations.

\section{Strength and limitations of the current study}

The strengths of this study come from the pooled the findings from longitudinal cohort studies and studies with externally documented childhood maltreatment, thus avoiding the issue of recall bias, effort after meaning and potential false memories. The studies reviewed here used strong mental health measures, are relatively recent, and are of good quality. PAF estimates show how the incidence of depression and anxiety could be substantially decreased by reducing childhood abuse.

However, there are several limitations. First, the small numbers of articles reviewed is an obvious limitation. It is unfortunate that more studies did not meet our stringent inclusion/exclusion criteria. Second, the studies reviewed are not representative of large sections of world's population with the studies coming from the USA (4), Australia (2), and New Zealand (2). Studies from developing countries are lacking. PAFs measures used the global prevalence of child abuse (both in general and specific types), which is more generalizable. Therefore, PAF estimates may be influenced by inconsistent measures between the global prevalence of maltreatment and associations between maltreatment and depression and anxiety observed in this meta-analysis. Third, heterogeneity was high in 3 of 4 analyses indicating substantial variation in the degree of association between childhood maltreatment and mental health outcomes in the studies reviewed. This reinforces the need for standardization in the measurement of childhood maltreatment and its various types and suggests that there may be significant moderators influencing the maltreatment and mental health relationship. There is a need for better tracking of potential moderators in future studies of childhood abuse. Fourthly, this review only included studies without recall bias in maltreatment assessment. The nature of these abuse reports often deals with more severe cases. Because the worldwide prevalence of child abuse does not provide data by severity levels, we used the crude overall prevalence to calculate PAFs. The estimates of PAFs may be influenced by the severity levels of child abuse. Finally, most selected studies, except one, did not report whether the outcome of interest (depression/anxiety) was present at baseline - in early childhood. Thus using strict criteria no causality can be inferred, as there is a lack of baseline data on depression and anxiety. Obviously, randomized clinical trials cannot (and should not) be conducted to examine the relationship between childhood maltreatment and depression and anxiety, therefore we are left with observational studies and meta-analyses of observational studies or naturally occurring experiments as our source of evidence. However, the weight of collaborating evidence suggests that a causal relationship plausibly exists.

\section{Conclusion}

Using externally documented measures of maltreatment thus avoiding the potential criticism of recall bias and false memory, this systematic review provides robust evidence about the effects of childhood maltreatment on the subsequent incidence of depression and anxiety in adulthood. The calculated PAFs showed the large reduction in the incidence of depression and anxiety that could result from reducing the prevalence of childhood maltreatment. This analysis reinforces the need for legal, health and social services initiatives aimed at reducing 
the prevalence of childhood maltreatment and for research that examines the factors that diminish the impact of childhood abuse on mental health.

\section{Supplementary material}

For supplementary material accompanying this paper visit http://dx.doi.org/10.1017/S0033291715002743.

\section{Acknowledgements}

M. Li was funded by the Western Regional Training Centre for Health Services Research (WRTC), Canada.

\section{Declaration of Interest}

None.

\section{References}

Afifi TO, MacMillan HL, Boyle M, Tailliew T, Cheung K, Sareen J (2014). Child abuse and mental disorders in Canada. Canadian Medical Association Journal 186, E324E332.

APA (2013). Diagnostic and Statistical Manual of Mental Disorders, 5th edn. American Psychiatric Association: Washington.

Barnes DE, Yaffe K (2011). The projected effect of risk factor reduction on Alzheimer's disease prevalence. Lancet Neurology 10, 819-828.

Benichou J (2001). A review of adjusted esimators of attributable risk. Statistical Methods in Medical Research 10, 195-216.

Bolton JM, Robinson J (2010). Population-attributable fractions of Axis I and Axis II mental disorders for suicide attempts: findings from a representative sample of the adult, noninstitutionalized US population. American Journal of Public Health 100, 2473-2480.

Briere JN, Elliott DM (1994). Immediate and long-term impacts of child sexual abuse. Future of Children 4, 54-69.

Brown J, Cohen P, Johnson JG, Smailes EM (1999). Childhood abuse and neglect: specificity of effects on adolescent and young adult depression and suicidality. Journal of American Academy of Child and Adolescent Psychiatry 38, 1490-1496.

Butchart A, Harvey AP, Furniss T (2006). Preventing child maltreatment: a guide to taking action and generating evidence. Geneva $(\mathrm{CH})$ : World Health Organization and International Society for Prevention of Child Abuse and Neglect (http://whqlibdoc.who.int/publications/2006/ 9241594365_eng.pdf). Accessed 20 November 2012.

Chen LP, Murad MH, Paras ML, Colbenson KM, Sattler AL, Goranson EN, Elamin MB, Seime RJ, Shinozaki G, Prokop LJ, Zirakzadeh A (2010). Sexual abuse and lifetime diagnosis of psychiatric disorder: systematic review and meta-analysis. Mayo Clinic Proceedings 85, 618-626.

Cicchetti D, Toth SL (2005). Child maltreatment. Annual Review of Clinical Psychology 1, 409-438.
Colman I, Kingsbury M, Garad Y, Zeng Y, Naicker K, Patten S, Jones PB, Wild TC, Thompson AH (2015). Consistency in adult reporting of adverse childhood experiences. Psychological Medicine. Published online: 29 October 2015. doi:10.1017/S0033291715002032.

Coughlin SS (1990). Recall bias in epidemiologic studies. Journal of Clinical Epidemiology 43, 87-91.

Cutajar MC, Mullen PE, Ogloff JRP, Thomas SD (2010). Psychopathology in a large cohort of sexually abused children followed up to 43 years. Child Abuse and Neglect 34, 813-822.

Cutuli JJ, Ranby KL, Cicchetti D, Englund MM, Egeland B (2013). Contributions of maltreatment and serotonin transporter genotype to depression in childhood, adolescence, and early adulthood. Journal of Affective Disorders 149, 30-37.

Danese A, Moffitt TE, Harrington HL, Milne BJ, Polanczyk G, Pariante CM, Poulton R, Caspi A (2009). Adverse childhood experiences and adult risk factors for age-related disease: depression, inflammation, and clustering of metabolic risk markers. Archives of Pediatrics and Adolescent Medicine 163, 1135-1143.

Egger M, Davey SG, Schneider M, Minder C (1997). Bias in meta-analysis detected by a simple, graphical test. British Medical Journal 315, 629-634.

Fergusson DM, Horwood LJ, Woodward LJ (2000). The stability of child abuse reports: a longitudinal study of the reporting behavior of young adults. Psychological Medicine 30, 529-544.

Hardt J, Rutter M (2004). Validity of adult retrospective reports of adverse childhood experiences: review of the evidence. Journal of Child Psychology and Psychiatry 45, 260-273.

Herringa RJ, Birn RM, Ruttle PL, Burghy CA, Stodola DE, Davidson RJ, Essex MJ (2013). Childhood maltreatment is associated with altered fear circuitry and increased internalizing symptoms by late adolescence. Proceedings of the National Academy of Sciences USA 110, 19119-19124.

Higgins JP, Thompson SG, Deeks JJ, Altman DG (2003). Measuring inconsistency in meta-analyses. British Medical Journal 327, 557-560.

Maniglio R (2009). The impact of child sexual abuse on health: a systematic review of reviews. Clinical Psychology Review 29, 647-657.

Maniglio R (2010). Child sexual abuse in the etiology of depression: a systematic review of reviews. Depression and Anxiety 27, 631-642.

Maniglio R (2012). Child sexual abuse in the etiology of anxiety disorders: a systematic review of reviews. Trauma, Violence, and Abuse 14, 96-112.

Maughan B, Pickles A, Quinton D (1995). Parental hostility, childhood behaviour, and adult social functioning. In Coercion and Punishment in Long Term Perspectives (ed. J. McCord), pp. 34-58. Cambridge University Press: New York.

Meng X, D'Arcy C (2013). The projected effect of increasing physical activity on reducing the prevalence of common mental disorders among Canadian men and women: a national population-based community study. Preventive Medicine 56, 59-63. 
Meng X, D'Arcy C (2014). The projected effect of risk factor reduction on major depression incidence: a 16-year longitudinal Canadian Cohort of the National Population Health Survey. Journal of Affective Disorders 158, 56-61.

McCrory E, De Brito SA, Viding E (2010). Research review: the neurobiology and genetics of maltreatment and adversity. Journal of Child Psychology and Psychiatry 51, 1079-1095.

Moher D, Liberati A, Tetzlaff J, Altman D (2009). Preferred reporting items for systematic reviews and meta-analyses: the PRISMA statement. PLoS Medicine 6, e1000097.

Nanni V, Uher R, Danese A (2012). Childhood maltreatment predicts unfavorable course of illness and treatment outcome in depression: a meta-analysis. American Journal of Psychiatry 169, 141-151.

Neumann DA, Houskamp BM, Pollock VE (1996). The long-term sequelae of childhood sexual abuse in women: a meta-analytic review. Child Maltreatment 1, 6-16.

Norman RE, Byambaa M, De R, Butchart A, Scott J, Vos T (2012). The long-term health consequences of child physical abuse, emotional abuse, and neglect: a systematic review and meta-analysis. PLoS Medicine 9, e1001349.

Northridge ME (1995). Annotation: public health methods-attributable risk as a link between causality and public health action. American Journal of Public Health 85, 1202-1203.

Paolucci EO, Genuis ML, Violato C (2010). A meta-analysis of the published research on the effects of child sexual abuse. Journal of Psychology: Interdisciplinary and Applied 135, 17-36.

Robins LN, Schoenberg SP, Holmes SJ, Ratcliff KS, Benham A, Works J (1985). Early home environment and retrospective recall: a test of concordance between siblings with and without psychiatric disorders. American Journal of Orthopsychiatry 55, 27-41.

Rockhill B, Newman B, Weinberg C (1998). Use and misuse of population attributable fractions. American Journal of Public Health 88, 15-19.

Sareen J, Belik SL, Afifi TO, Asmundson GJ, Cox BJ, Stein MB (2008). Canadian military personnel's population attributable fractions of mental disorders and mental health service use associated with combat and peacekeeping operations. American Journal of Public Health 98, 2191-2198.

Scott KM, McLaughlin KA, Smith DAR, Ellis PM (2012). Childhood maltreatment and DSM-IV adult mental disorders: comparison of prospective and retrospective findings. British Journal of Psychiatry 200, 469-475.

Spataro J, Mullen PE, Burgess PM, Wells DL, Moss SA (2004). Impact of child sexual abuse on mental health. British Journal of Psychiatry 184, 416-412.

Stoltenborgh M, Bakermans-Kranenburg MJ, Alink LRA, IJzendoorn MH (2015). The prevalence of child maltreatment across the globe: review of a series of mega-analysis. Child Abuse Review 24, 37-50.

Stoltenborgh M, IJzendoorn MH, Euser EM, Bakermans-Kranenburg MJ (2011). A global perspective on child sexual abuse: meta-analysis of prevalence around the world. Child Maltreatment 16, 79-101.

Stroup D, Berlin J, Morton S, Ingram O, Williamson G, Rennie D, Moher D, Becker BJ, Sipe TA, Thacker SB, the
Meta-analysis Of Observational Studies in Epidemiology (MOOSE) Group (2000). Meta-analysis of observational studies in epidemiology: a proposal for reporting. Journal of the American Medical Association 283, 2008-2012.

Taylor SE, Brown JD (1988). Illusion and wellbeing: a social psychological perspective on mental health. Psychological Bulletin 103, 193-210.

Toth SL, Manly JT, Cicchetti D (1992). Child maltreatment and vulnerability to depression. Development and Psychopathology 4, 97-112.

Vos T, Flaxman AD, Naghavi M, Lozano R, Michaud C, Ezzati M, Shibuya K, Salomon JA, Abdalla S, Aboyans V, Abraham J, Ackerman I, Aggarwal R, Ahn SY, Ali MK, Alvarado M, Anderson HR, Anderson LM, Andrews KG, Atkinson C, Baddour LM, Bahalim AN, Barker-Collo S, Barrero LH, Bartels DH, Basáñez MG, Baxter A, Bell ML, Benjamin EJ, Bennett D, Bernabé E, Bhalla K, Bhandari B, Bikbov B, Bin Abdulhak A, Birbeck G, Black JA, Blencowe $\mathrm{H}$, Blore JD, Blyth F, Bolliger I, Bonaventure A, Boufous S, Bourne R, Boussinesq M, Braithwaite T, Brayne C, Bridgett L, Brooker S, Brooks P, Brugha TS, Bryan-Hancock C, Bucello C, Buchbinder R, Buckle G, Budke CM, Burch M, Burney P, Burstein R, Calabria B, Campbell B, Canter CE, Carabin H, Carapetis J, Carmona L, Cella C, Charlson F, Chen H, Cheng AT, Chou D, Chugh SS, Coffeng LE, Colan SD, Colquhoun S, Colson $\mathrm{KE}$, Condon J, Connor MD, Cooper LT, Corriere $\mathrm{M}$, Cortinovis M, de Vaccaro KC, Couser W, Cowie BC, Criqui MH, Cross M, Dabhadkar KC, Dahiya M, Dahodwala N, Damsere-Derry J, Danaei G, Davis A, De Leo D, Degenhardt L, Dellavalle R, Delossantos A, Denenberg J, Derrett S, Des Jarlais DC, Dharmaratne SD, Dherani M, Diaz-Torne C, Dolk H, Dorsey ER, Driscoll T, Duber H, Ebel B, Edmond K, Elbaz A, Ali SE, Erskine H, Erwin PJ, Espindola P, Ewoigbokhan SE, Farzadfar F, Feigin $V$, Felson DT, Ferrari A, Ferri CP, Fèvre EM, Finucane MM, Flaxman S, Flood L, Foreman K, Forouzanfar MH, Fowkes FG, Franklin R, Fransen M, Freeman MK, Gabbe BJ, Gabriel SE, Gakidou E, Ganatra HA, Garcia B, Gaspari F, Gillum RF, Gmel G, Gosselin R, Grainger R, Groeger J, Guillemin F, Gunnell D, Gupta R, Haagsma J, Hagan $H$, Halasa YA, Hall W, Haring D, Haro JM, Harrison JE, Havmoeller R, Hay RJ, Higashi H, Hill C, Hoen B, Hoffman H, Hotez PJ, Hoy D, Huang JJ, Ibeanusi SE, Jacobsen $\mathrm{KH}$, James $\mathrm{SL}$, Jarvis $\mathrm{D}$, Jasrasaria R, Jayaraman S, Johns N, Jonas JB, Karthikeyan G, Kassebaum N, Kawakami N, Keren A, Khoo JP, King CH, Knowlton LM, Kobusingye O, Koranteng A, Krishnamurthi R, Lalloo R, Laslett LL, Lathlean T, Leasher JL, Lee YY, Leigh J, Lim SS, Limb E, Lin JK, Lipnick M, Lipshultz SE, Liu W, Loane M, Ohno SL, Lyons R, Ma J, Mabweijano J, MacIntyre MF, Malekzadeh R, Mallinger L, Manivannan S, Marcenes W, March L, Margolis DJ, Marks GB, Marks R, Matsumori A, Matzopoulos R, Mayosi BM, McAnulty JH, McDermott MM, McGill N, McGrath J, Medina-Mora ME, Meltzer M, Mensah GA, Merriman TR, Meyer AC, Miglioli V, Miller M, Miller TR, Mitchell PB, Mocumbi AO, Moffitt TE, Mokdad AA, Monasta L, Montico M, Moradi-Lakeh M, 
Moran A, Morawska L, Mori R, Murdoch ME, Mwaniki MK, Naidoo K, Nair MN, Naldi L, Narayan KM, Nelson PK, Nelson RG, Nevitt MC, Newton CR, Nolte S, Norman P, Norman R, O'Donnell M, O'Hanlon S, Olives C, Omer SB, Ortblad K, Osborne R, Ozgediz D, Page A, Pahari B, Pandian JD, Rivero AP, Patten SB, Pearce N, Padilla RP, Perez-Ruiz F, Perico N, Pesudovs K, Phillips D, Phillips MR, Pierce K, Pion S, Polanczyk GV, Polinder S, Pope CA III, Popova S, Porrini E, Pourmalek F, Prince M, Pullan RL, Ramaiah KD, Ranganathan D, Razavi H, Regan M, Rehm JT, Rein DB, Remuzzi G, Richardson K, Rivara FP, Roberts T, Robinson C, De Leòn FR, Ronfani L, Room R, Rosenfeld LC, Rushton L, Sacco RL, Saha S, Sampson U, Sanchez-Riera L, Sanman E, Schwebel DC, Scott JG, Segui-Gomez M, Shahraz S, Shepard DS, Shin H, Shivakoti R, Singh D, Singh GM, Singh JA, Singleton J, Sleet DA, Sliwa K, Smith E, Smith JL, Stapelberg NJ, Steer A, Steiner T, Stolk WA, Stovner LJ, Sudfeld C, Syed S, Tamburlini G, Tavakkoli M, Taylor HR, Taylor JA, Taylor WJ, Thomas B, Thomson WM, Thurston GD, Tleyjeh IM, Tonelli M, Towbin JA, Truelsen T, Tsilimbaris MK, Ubeda C, Undurraga EA, van der Werf MJ, van Os J, Vavilala MS, Venketasubramanian N, Wang M, Wang W, Watt K, Weatherall DJ, Weinstock MA, Weintraub R, Weisskopf MG, Weissman MM, White RA, Whiteford $H$, Wiersma ST, Wilkinson JD, Williams HC, Williams SR, Witt E, Wolfe F, Woolf AD, Wulf S, Yeh PH, Zaidi AK, Zheng ZJ, Zonies D, Lopez AD, Murray CJ, AlMazroa MA, Memish ZA (2012). Years lived with disability (YLDs) for 1160 sequelae of 289 diseases and injuries 1990-2010: a systematic analysis for the Global Burden of Disease Study 2010. Lancet 380, 2163-2196.

Wells G, Shea B, O'Connell D, Petersen J, Welch V, Losos M, Tugwell P (2012). The Newcastle-Ottawa Scale (NOS) for assessing the quality of nonrandomized studies in meta-analyses. Ottawa Hospital Research Institute: Ottawa (http://www.ohri.ca/programs/clinical_epidemiology/ oxford.asp). Accessed 12 February 2015.

Whiteford HA, Degenhardt L, Rehm J, Baxter AJ, Ferrari AJ, Erskine HE, Charlson FJ, Norman RE, Flaxman AD, Johns N, Burstein R, Murray CJL, Vos T (2013). Global burden of disease attributable to mental and substance use disorders: findings from the Global Burden of Disease Study 2010. Lancet 382, 1575-1586.

Widom CS (1999). Posttraumatic Stress Disorder in abused and neglected children grown up. American Journal of Psychiatry 156, 1223-1229.

Widom CS, DuMont K, Czaja SJ (2007). A prospective investigation of major depressive disorder and comorbidity in abused and neglected children grown up. Archives of General Psychiatry 64, 49-56.

WHO (1992). The ICD-10 Classification of Mental and Behavioural Disorders: Clinical Descriptions and Diagnostic Guidelines. World Health Organization: Geneva.

WHO (2012). Depression: Fact Sheet (http://www.who.int/ mediacentre/factsheets/fs369/en/). World Health Organization. Accessed 10 February 2015.

WHO (2014). Media Centre: Child Maltreatment. (http:// www.who.int/mediacentre/factsheets/fs150/en/index.html). World Health Organization. Accessed 12 March 2015. 